\section{Reelin expression in human liver of patients with chronic hepatitis C infection}

\author{
Simone Carotti, ${ }^{1}$ Giuseppe Perrone, ${ }^{2}$ \\ Michelina Amato, ${ }^{2}$ \\ Umberto Vespasiani Gentilucci, ${ }^{3}$ \\ Daniela Righi, ${ }^{2}$ Maria Francesconi, ${ }^{1}$ \\ Claudio Pellegrini, ${ }^{2}$ Francesca Zalfa, ${ }^{1}$ \\ Maria Zingariello, ${ }^{1}$ Antonio Picardi, ${ }^{3}$ \\ Andrea Onetti Muda, ${ }^{2}$ Sergio Morini ${ }^{1}$ \\ ${ }^{1}$ Laboratory of Microscopic and \\ Ultrastructural Anatomy, CIR, Campus \\ Bio-Medico University, Rome \\ ${ }^{2}$ Department of Pathology, \\ Campus Bio-Medico University, Rome \\ ${ }^{3}$ Internal Medicine and Hepatology Unit, \\ Campus Bio-Medico University, Rome, \\ Italy
}

\section{Abstract}

Reelin is a secreted extracellular glycoprotein that plays a critical role during brain development. Several studies have described Reelin expression in hepatic stellate cells of the human liver. In order to investigate the possible role of Reelin in the process of hepatic fibrogenesis, in this study we investigated Reelin expression in the liver tissue of patients infected with the Hepatitis C Virus (HCV). On this basis, Reelin expression was analysed by immunohistochemistry during liver biopsies of 81 patients with HCV-related chronic hepatitis. A Knodell score was used to stage liver fibrosis. Hepatic stellate cells/myofibroblast immunohistochemical markers (CRBP-1, alpha-SMA) were also evaluated. As further confirmed by colocalization experiments (Reelin + CRBP1), Reelin protein was expressed by hepatic stellate cells/myofibroblasts, and a significant positive correlation was found between Reelin expression and the stage of liver fibrosis $(\mathrm{P}=0.002)$. Moreover, Reelin correlated with $\mathrm{CRBP}-1$ positive cells $(\mathrm{P}=0.002)$, but not with alpha-SMA, suggesting that Reelin should not be regarded as a marker of hepatic stellate cells/myofibroblasts differentiation but rather as a functional protein expressed during some phases of liver fibrosis. Furthermore, Disabled-1 (Dab1), a Reelin adaptor protein, was expressed in cells of ductular reaction suggesting a paracrine role for Reelin with regards these elements. In conclusion, Reelin was expressed by human hepatic stellate cells/myofibroblasts and the number of these cells increased significantly in the lobule as the liver fibrosis progressed, suggesting a role for Reelin in the activation of hepatic stellate cells/myofibroblasts during liver injury. Reelin may potentially be incorporated into liver injury evaluations in combination with other histological data.

\section{Introduction}

Reelin is a $420 \mathrm{kDa}$ secreted extracellular glycoprotein that plays a critical role during brain development and maturation. ${ }^{1,2}$ Reelin is thought to guide migrating neurons by interacting with two cell surface receptors, the very low density lipoprotein receptor (VLDLR), and the apolipoprotein E receptor 2 (ApoER2). ${ }^{3-5}$ In the downstream signal transduction, Disabled-1 (Dab1) is essential. Dab1 is an intracellular adaptor protein that binds the cytoplasmic tail of Reelin receptors ${ }^{6}$ and upon Reelin binding, becomes phosphorylated on tyrosine residues. Dab1 phosphorylation is required for cellular migration. ${ }^{7}$

Reelin was also found to be expressed in adult peripheral tissues suggesting a wide spectrum of biological functions. ${ }^{8}$ Smalheiser et al. demonstrated that the adult liver expressed one-third of the Reelin mRNA concentration found in an adult mouse cerebral cortex, being a leading candidate to produce and maintain the circulating Reelin pool. ${ }^{9}$ Reelin expression in the human liver was demonstrated in hepatic stellate cells (HSCs) rather than hepatocytes. ${ }^{10,11}$ Moreover, Reelin has been described as one of the extracellular matrix proteins upregulated in the fibrotic liver, ${ }^{10,12}$ suggesting it has a key role in the fibrogenic process during the liver injury. ${ }^{13}$ Botella-Lopez et al. consistently demonstrated an increase in plasma Reelin levels in patients with liver cirrhosis. ${ }^{13}$

The Hepatitis C Virus (HCV) is one of the major causes of chronic liver disease and, in a significant number of patients, chronic hepatitis $\mathrm{C}$ will progress to cirrhosis and hepatocellular carcinoma, which represents the end-stage fibrotic liver disease. ${ }^{14}$ Currently, the relationship between Reelin expression and liver fibrosis is still unclear and, to date, there have been few data concerning Reelin expression in human fibrotic liver tissue. ${ }^{15}$

HSCs are a resident mesenchymal cell type located in the subendothelial space of Disse, interposed between sinusoidal endothelium and hepatocytes. ${ }^{16}$ Following liver injury, HSCs become activated cells with myofibroblast (MF) features, and change their phenotype conversion from
Correspondence: Giuseppe Perrone, Department of Pathology, Campus BioMedico University, Via Alvaro del Portillo 200, 00128 Roma, Italy.

Tel. +39.06.225411155 - Fax. +39.06.22541456.

E-mail: g.perrone@unicampus.it

Key words: Reelin; liver fibrosis; HCV; hepatic stellate cells; Dab1.

Contributions: SC, GP, study conception, participation in its presentation and coordination; $\mathrm{DR}, \mathrm{CP}, \mathrm{MF}, \mathrm{MZ}, \mathrm{UV}$, experiments performing, data acquisition; SC, GP, MA, data analysis and paper composition; FZ, AP, AOM, SM, critical review to ensure robust intellectual content. All authors read and approved the final manuscript. SC and GP contributed equally to the paper.

Conflicts of interest: the authors declare no conflict of interest.

Received for publication: 27 October 2016. Accepted for publication: 1 February 2017.

This work is licensed under a Creative Commons Attribution-NonCommercial 4.0 International License (CC BY-NC 4.0).

CC Copyright S. Carotti et al., 2017

Licensee PAGEPress, Italy

European Journal of Histochemistry 2017; 61:2745 doi:10.4081/ejh.2017.2745

resting vitamin A-rich cell type (quiescent HSC) into one that has lost vitamin A droplets, capable of increased proliferation, of contraction and of releasing proinflammatory, profibrogenic, and promitogenic cytokines. ${ }^{17}$ Activated HSCs/MFs show enhanced migration and the deposition of extracellular matrix components, ${ }^{16}$ leading to liver fibrosis and eventually cirrhosis. ${ }^{18}$ On this basis, researchers have focused on the characterization of activated HSCs/MFs which would predict the clinical course of chronic liver disease (CLD). ${ }^{19-22}$ Over the last decades many immunohistochemical HSC/MF markers have been described in rat or mouse models and in human liver. Known HSC/MF markers include alphaSmooth Muscle Actin (alpha-SMA) ${ }^{23}$ and Cellular Retinol-Binding Protein-1 (CRBP1). ${ }^{24}$ CRBP-1 is a key component of the retinoid signalling pathway and was proposed as an unambiguous marker of quiescent and activated HSCs/MFs since it is highly expressed in both normal and pathological liver samples. ${ }^{24,25}$ Alpha-SMA represents the traditional marker of fully activated HSCs/MFs and is related with their migratory and contractile properties. It has been extensively used in order to identify 
HSC/MF markers of clinical utility. ${ }^{20,22}$ The activation and proliferation of HSCs/MFs are often observed in close anatomical and temporal relationship with hepatic progenitor cells (HPCs) of the ductular reaction (DR) ${ }^{26,27}$ HPCs of the DR have an increasingly documented role in promoting liver fibrosis, such that they were considered the pacemaker of the fibrotic process. ${ }^{28}$ At the tissue level, HPCs of the DR can be identified according to their shape, portal and periportal localization and immunohistochemical features. The expression of Cytokeratin 7 (CK7), Cytokeratin 19 (CK19) and Epithelial Cell Adhesion Molecule (EpCAM), have been widely used to quantify HPCs of the DR, based on their proven reproducibility. ${ }^{29-34}$ It would be of great interest to identify novel $\mathrm{HSC} / \mathrm{MF}$ markers that are functionally related with HPCs and the DR, since both HPCs and HSCs/MFs play an important role in liver regeneration and cicatrization. A better knowledge of the cross-talk between HSCs/MFs and HPCs could furnish new insight into the hepatic reparative and fibrogenic process.

It was on the basis of these concerns, and with a view to shedding further light on the expression of Reelin in human liver injury, that we investigated hepatic Reelin expression in a large series of patients with HCV-related chronic hepatitis, and verified its relationship with the other histological and immunohistochemical markers used to reflect activity and severity of liver disease.

\section{Materials and Methods}

\section{Patients and histopathology}

Eighty-one patients with HCV-related CLD underwent a liver biopsy for diagnostic purposes at the Campus Bio-Medico Hospital of Rome and were included in the study. The inclusion criteria were in all cases: i) before their liver biopsy or surgery was performed, patients had given and signed their informed consent for the use of part of their liver tissue for research studies; ii) complete clinical data and paraffinembedded liver tissue from biopsy specimens or resected liver was available. The exclusion criteria were: i) a history of alcohol abuse or coinfection with hepatitis B or human immunodeficiency virus; ii) a diagnosis of hepatocellular carcinoma.

Normal liver tissue was obtained from autoptic liver specimens taken from three patients with a histological absence of liver disease and from histologically healthy margins of liver resected for tumour metas- tasis. Biopsies were scored in accordance with the Knodell classification. The Knodell histology activity index (HAI) is widely regarded as the benchmark for the objective, semiquantitative, reproducible description of the various morphological lesions of chronic hepatitis. ${ }^{35}$ The lesions of fibrosis and parenchymal or vascular remodelling are referred to as the 'stage' and indicate long-term disease progression. ${ }^{35}$ Moreover, the DR was recognized by evaluating immunohistochemical staining for CK $7 .{ }^{36}$ The DR was semiquantitatively graded (0-4) by an experienced pathologist (SC) Gadd et al. ${ }^{37}$ Perisinusoidally located stellate shaped cells residing in the parenchymal lobules or nodules and stellate- or spindle-shaped cells at the interface between the parenchyma and the portal tract or between the parenchyma and the septa, as well as those residing in the portal tracts and the fibrotic septa were identified as HSCs/MFs. ${ }^{38,39}$

The study protocol complied with the ethical guidelines of the 1975 Declaration of Helsinki and was approved by the local Ethics Committee.

\section{Immunohistochemical staining}

Reelin and CRBP-1 expression were investigated by immunohistochemistry performed on 3- $\mu \mathrm{m}$ thick consecutive sections obtained from formalin-fixed tissue embedded in paraffin. Moreover, the expression of Dab1, alpha-SMA and CK7 was evaluated in a subgroup of patients (20 cases).

After deparaffination and antigen retrieval with Citrate Buffer ( $\mathrm{pH}$ 6) (Dako, Glostrup, Denmark), the blockage of the endogenous peroxidase activity by incubation in 3\% hydrogen peroxide ( $5 \mathrm{~min}$ ), and the blockage of the endogenous biotin by the Biotin Blocking System (Dako, Milan, Italy) were subsequently performed. The sections were then washed 3 times in phosphate-buffered saline and incubated for $1 \mathrm{~h}$ at room temperature with the followings primary antibodies: anti-Reelin mouse monoclonal antibody (Chemicon: 142 clone; 1:250), ${ }^{40}$ anti-CRBP-1 rabbit polyclonal antibody (FL-135 clone; 1:100; Santa Cruz Biotechnology, Santa Cruz, CA, USA), ${ }^{24}$ anti-Dab1 rabbit polyclonal antibody (H-103 clone; 1:100; Santa Cruz Biotechnology), ${ }^{41}$ anti-alpha-SMA mouse monoclonal antibody (1A4 clone; 1:100, Dako), anti-CK7 mouse monoclonal antibody (OV-TL12/30 clone; 1:100; Dako). ${ }^{20}$ Negative controls were obtained by omitting primary antibodies. Positive internal controls in the liver tissue were available for Reelin and alpha-SMA, being neural structure (fibers and ganglion) ${ }^{40}$ and arterial walls ${ }^{20}$ respectively. After 3 washings in phosphate-buffered saline, the sections were incubated in the HRP-Polymer Kit (Biocare Medical, Concord, CA, USA) for $30 \mathrm{~min}$ and after further washings they were exposed to Betazoid DAB (Biocare Medical) as chromogen. An immunohistochemical evaluation of the HSC/MF markers tested was performed as follows. In order to evaluate the markers' expression in the hepatic lobule, the analysis was performed in consecutive slides by counting the number of immunoreactive $\mathrm{HSC} / \mathrm{MF}$ cells in images taken from 5 representative microscopic fields (at 200X magnification). In the portal tracts and the septa and at the interface between them and the parenchyma, immunoreactivity was scored as follows (as previously described): ${ }^{39} 0$, no positivity; 0.5 , positivity of less than $10 \%$ of HSCs/MFs; 1 , positivity of $10 \%$ to $20 \%$ of HSCs/MFs; 2, positivity of $20 \%$ to $50 \%$ of HSCs/MFs; 3, positivity of more than $50 \%$ of HSCs/MFs. Images were obtained using the Imaging Software NIS-Elements. Double labelling experiments were performed with an anti-Reelin mouse monoclonal antibody (142 clone; 1:250; Chemicon International, Inc., Temecula, CA, USA) and an anti-CK19 rabbit monoclonal antibody (EP72 clone; 1:100; Epitomics, Burlingame, CA, USA) with the polymer detection kit MACH2 Double Stain 2 (Biocare Medical), Betazoid DAB and Warp Red Chromogen Kit (Biocare Medical).

\section{Immunofluorescence}

Immunofluorescence staining was performed with the same anti-Reelin, antiCRBP-1 and anti-Dab1 antibodies used for immunohistochemistry, since they can also be visualized and evaluated in sections stained using the immunofluorescence technique. The EpCAM antibody (dilution 1:25; mouse monoclonal, clone C-10; Santa Cruz Biotechnology) ${ }^{34}$ was also used. In order to characterize the HSCs/MFs' Reelin expression, double-labelling experiments (antiReelin + anti-CRBP-1) were performed. Moreover, double-labelling experiments (anti-Dab1 + anti-EpCAM) were performed in order to verify the location of Dab1 expression. Incubation with primary antibodies was followed by Alexa Fluor 488 (green; dilution 1:50; goat anti-mouse; Invitrogen, Carlsbad, CA, USA) for Reelin and EpCAM, and by Alexa Fluor 568 (red; dilution 1:50; donkey anti-rabbit; Invitrogen) for CRBP-1 and Dab1. Nuclear counterstaining was achieved with DAPI. Fluorescence images were collected using an Eclipse80i Nikon microscope (Nikon, 
Tokyo, Japan). Acquisition was carried out using NIS-Elements the Imaging Software (Nikon).

\section{Statistical analysis}

Variables are expressed as the median and $95 \%$ confidence intervals (95\% CI). The statistical correlation between the clinicopathologic, morphologic, and immunohistochemical parameters was tested using a 2-sided Spearman test. The difference was analyzed according to Mann-Whitney Utests for non-parametric independent variables. Multivariate linear regression analysis was applied to verify if the association between the Reelin-positive HSCs/MFs and the DR was independent of dependent on the number of alpha-SMA-positive or CRBP-1-positive HSCs/MFs. A P $<0.05$ was considered statistically significant in 2tailed tests. SPSS software (ver. 17.00, SPSS, Chicago, IL, USA) was used for the statistical analysis.

\section{Results}

\section{Clinicopathological data}

Of the $81 \mathrm{HCV}$-patients, 40 (49.4\%) were women and $41(50.6 \%)$ were men. The median age at initial diagnosis was 56 years (age range 45 to 64 years). The clinicopathological data are summarized in Table 1. As expected, a significant positive correlation was found between the Knodell's grade and the stage of liver disease $(\mathrm{r}=0.26$; $\mathrm{P}<0.0001$ ). No statistical differences were found between the various Knodell's stages in terms of age and sex.

\section{Immunohistochemistry experiments}

Reelin immunostaining was observed in the cytoplasm of $\mathrm{HSCs} / \mathrm{MFs}$ localized in lobule tissue, both in normal and in pathological liver samples. Sometimes Reelin positive cells exhibited clear cytoplasmatic lipid droplets (Figure $1 \mathrm{~A}-\mathrm{C}$ ). Reelin positive HSCs/MFs were found, to a lesser
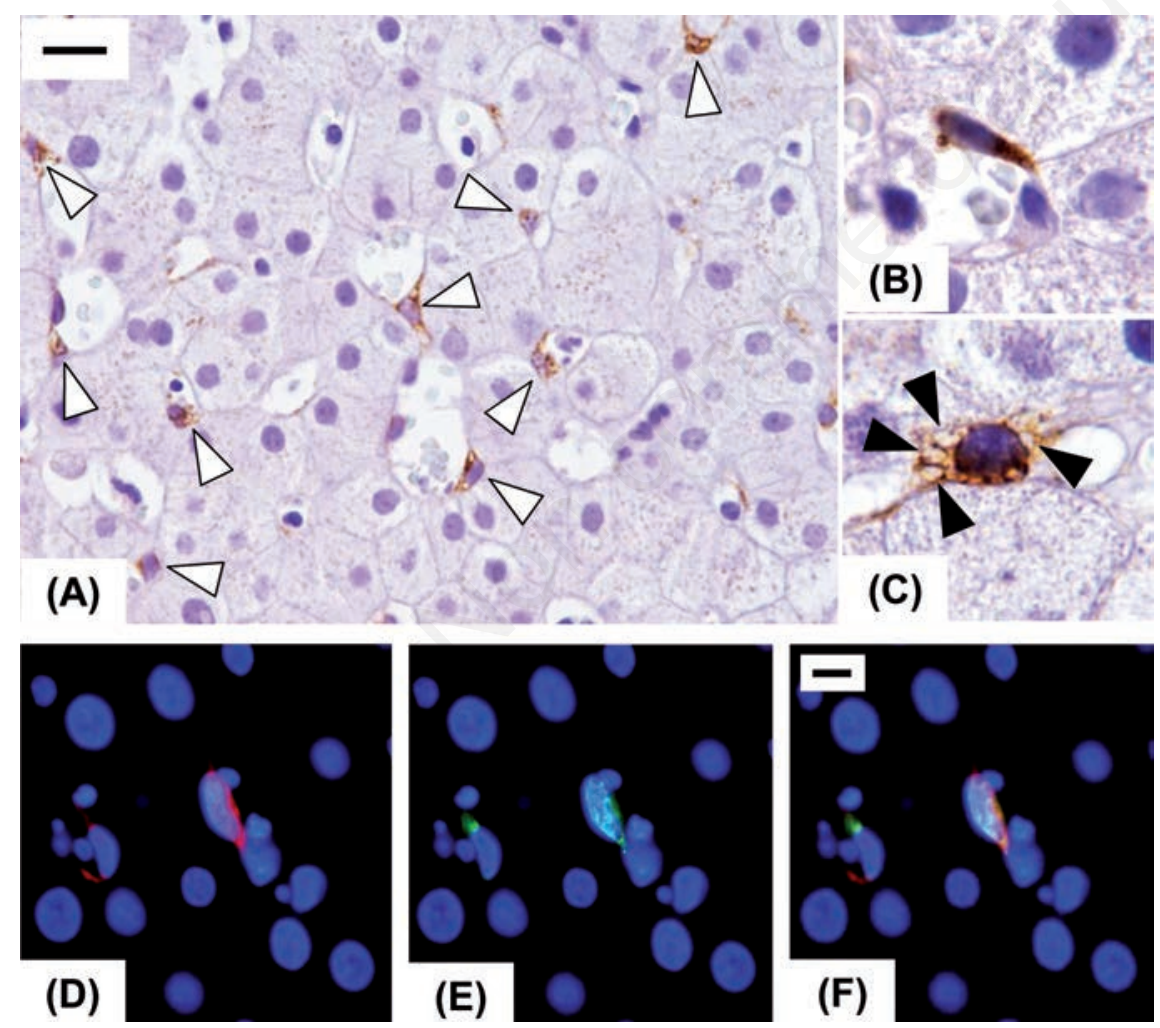

Figure 1. Immunohistochemical expression of Reelin in injured human liver in early fibrosis stage. Reelin expression was restricted to spindle shaped cells (open arrowheads), resembling hepatic stellate cells, located in the perisinusoidal space (A). Some of them are elongated with a typical morphology of activated stellate cells (B), others exhibit a quiescent phenotype characterized by the presence of lipid droplets (closed arrowheads) in the cytoplasm (C). Double-labelling experiments with a hepatic stellate cells marker (CRBP-1, red, D) and Reelin (green, E), confirmed that Reelin was expressed by hepatic stellate cells (merge, F). Original magnification: A9), X400; B,C), X1000; D), X1000; scale bars: A), $20 \mu \mathrm{m} ; \mathrm{D}), 10 \mu \mathrm{m}$.

degree, in enlarged portal tracts and fibrous septa, where cells lining putative lymphatic vessels were also Reelin-positive as previously described ${ }^{42}$ and where some small biliary ductules exhibited a mild Reelin expression (Figure 2 A-C). Moreover, Reelin expression was found in neural structures (fibers and ganglion) present in the tissue sections.

CRBP-1 was highly expressed in the cytoplasm of HSCs/MFs both in normal and in pathological liver samples, confirming CRBP-1 expression in both quiescent lobular HSCs and activated lobular and portal/septal HSCs/MFs cells (Figure 3 A-C). A scant CRBP-1 expression was observed in some interlobular bile ducts (Figure 3C). Hepatocytes were negative for Reelin and CRBP-1 immunostaining, then were used as a negative internal control.

Alpha-SMA, a marker of activated HSCs/MFs, was expressed by a few cells in normal liver tissue, whereas it was expressed by most $\mathrm{HSCs} / \mathrm{MFs}$ in cases of HCV-related liver disease (Figure 4 A-C).

Dab1, a Reelin adaptor protein, was highly expressed in the cytoplasm and nuclei of bile ducts of the DR and also, to a lower degree, in normal bile ducts of portal tracts. Notably, Dab1 was not expressed in HSCs/MFs and hepatocytes (Figure 5 A,B).

\section{Double-labelling experiments}

\section{by fluorescent and light microscopy}

Double-labelling experiments were performed in order to characterize Reelin and, separately, Dab1-expressing cells by means of fluorescent microscopy. CRBP-1 expressing cells, perisinusoidal spindle shaped cells individuated as $\mathrm{HSCs} / \mathrm{MFs}$,

Table 1. Clinicopathological variables.

\begin{tabular}{lc} 
& No. of cases (\%) \\
No. of patients & 81 \\
Sex & \\
$\quad$ Female & $40(49.4 \%)$ \\
$\quad$ Male & $41(50.6) \%$ \\
\hline Age $56(45-64)$ & \\
HAI Grade & \\
1 & $6(7.4 \%)$ \\
$5-8$ & $28(34.6 \%)$ \\
$9-12$ & $35(43.2 \%)$ \\
$13-18$ & $12(14.8 \%)$ \\
\hline HAI Stage & \\
0 & $9(11.1 \%)$ \\
1 & $-443(53.1 \%)$ \\
3 & $18(22.2 \%)$ \\
4 & $11(13.6 \%)$ \\
\hline
\end{tabular}

HAI, histology activity index. 
were demonstrated to co-express Reelin (Figure 1D).

In order to confirm that Dab1 expressing cells are cells of DR, a marker of HPCs was tested in the areas of the DR, together with Dab1. EpCAM-positive cells, recognized as HPCs, were shown to co-express Dab1 (Figure 5 C-E).

Double labelling experiments by means of light microscopy were performed in order to investigate the spatial relationship between cells of DR and Reelin expressing cells. CK19-positive cells in the periportal area, having the morphological features of HPCs of DR, were localized close to Reelin positive HSCs/MFs (Figure 6A).

\section{HSCs/MFs markers and correlation with fibrosis stage}

The median of Reelin positive lobular HSCs/MFs in healthy and disease liver is set out in Table 2. Data showed a significant increase of Reelin positive lobular HSCs/MFs liver fibrosis progressed $(\mathrm{r}=0.32 ; \mathrm{p}=0.002)$ (Table 2; Figure $2 \mathrm{~A}-\mathrm{D})$. We used CRBP-1 in order to characterize the entire lobular HSCs/MFs population in liver samples. The median of CRBP-1 positive lobular HSCs/MFs in healthy and diseased liver is summarized in Table 2 . Correlation analysis showed that the number of CRBP-1 positive lobular HSCs/MFs increases in line with the fibrosis stage according to Knodell ( $\mathrm{r}=0.26 ; \mathrm{P}=0.012$ ), suggesting an expansion of the lobular HSC/MF population during fibrosis progression (Table 2; Figure 3 A-D).

In the same manner, the number of alpha-SMA positive HSCs/MFs in hepatic lobules increased significantly with fibrosis progression $(\mathrm{r}=0.61 ; \mathrm{P}<0.0001)$, confirming the role HSC/MF activation in fibrotic liver disease (Table 2; Figure 4 A-D). A significant correlation was also found between alpha-SMA and CRBP-1 positive lobular HSCs/MFs ( $\mathrm{r}=0.42 ; \mathrm{P}=0.012)$. Moreover, the number of Reelin and CRBP-1 positive lobular cells showed a significant positive correlation ( $\mathrm{r}=0.32 ; \mathrm{P}=0.002$ ). No correlation was found between Reelin and alphaSMA. The analysis of portal/septal Reelin or CRBP-1-positive HSCs/MFs confirmed a lower degree of expression in the portal tract and septa compared to that found in the hepatic lobule. The median scores for Reelin and CRBP-1 positive portal/septal HSCs/MFs are summarized as follows: 0.5 (CI 0.4-0.8) and 0 (CI 0-0.3) in healthy liver, 0.5 (CI 0.4-0.6) and 1 (CI 1.2-0.8) in diseased liver, for Reelin and CRBP-1 respectively. A significant difference $(\mathrm{P}<0.001)$ was found between CRBP-1positive HSCs/MFs in both healthy and diseased liver. The median score of alpha-
SMA-positive portal/septal HSCs/MFs was 0 (CI 0-0.2) in healthy liver and 1 (CI 1.1$1.8)$ in diseased liver $(\mathrm{P}<0.001)$. Moreover, the median scores for both CRBP-1-positive and alpha-SMA-positive portal/septal HSCs/MFs correlated with Knodell's stage of fibrosis $(\mathrm{r}=0.29, \mathrm{P}=0.018$ and $\mathrm{r}=0.63$, $\mathrm{P}<0.001$ for CRBP-1 and alpha-SMA, respectively). A significant correlation was also found between the median score of both CRBP-1-positive and alpha-SMA-positive portal/septal HSCs/MFs ( $\mathrm{r}=0.65$; $\mathrm{P}<0.001)$.
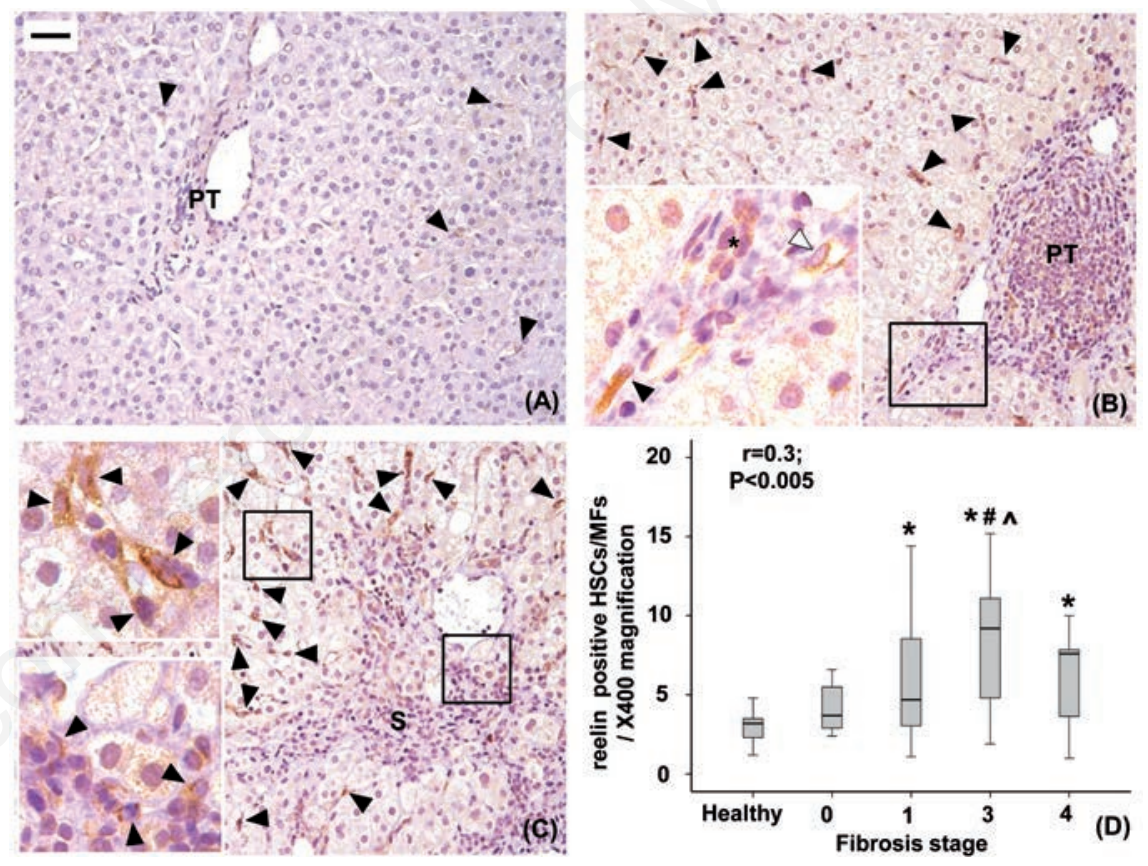

Figure 2. Immunohistochemical expression of Reelin in healthy livers (A), livers with mild to moderate fibrosis (B) and with severe fibrosis (C). Reelin positive hepatic stellate cells/myofibroblasts (close arrowheads) are located mainly in the lobule and less frequently in the portal tract (PT) or septa (S). Reelin expression was also detected in cells lining putative lymphatic vessels (open arrowheads) and, faintly, in biliary ductules $(*)$. The number of Reelin positive lobular HSCs/MFs increases with fibrosis progression $\left(\mathrm{r}=0.3, \mathrm{P}<0.05 ;{ }^{*} \mathbf{P}<0.05\right.$ vs healthy livers; $\# \mathbf{P}<\mathbf{0 . 0 5}$ vs stage $\mathbf{0}, \wedge \mathrm{P}<\mathbf{0 . 0 5}$ vs stage $\left.1, \mathrm{D}\right)$. Original magnification: X200; high power fields: X400; scale bar: $50 \mu \mathrm{m}$.

Table 2. Immunohistochemical analyses of lobular hepatic stellate cells / myofibroblasts markers.

\begin{tabular}{lcccccc} 
& $\begin{array}{c}\text { Healthy } \\
\text { liver }\end{array}$ & $\begin{array}{c}\text { Stage of } \\
\text { filbrosis 0 }\end{array}$ & $\begin{array}{c}\text { Stage of } \\
\text { filbrosis 1 }\end{array}$ & $\begin{array}{c}\text { Stage of } \\
\text { fibrosis } 3\end{array}$ & $\begin{array}{c}\text { Stage of } \\
\text { fibrosis } 4\end{array}$ & $\begin{array}{c}\text { P-value }^{\circ} \\
\text { Reelin-positive lobular HSCs/MFs }\end{array}$ \\
CRBP-1-positive lobular HSCs/MFs & $2.7(1.3-3.8)$ & $3.7(2.6-6.6)$ & $4.7(4.7-6.8)^{*}$ & $9.2(6.2-10.1)^{* * \wedge}$ & $7.6(4.0-8.2)^{*}$ & 0.006 \\
\hline Alpha SMA-positive lobular HSCs/MFs & $3.4(2.4-4.9)$ & $5.5(3.2-9.7)$ & $6.3(5.7-8.3)^{*}$ & $10.1(7.1-12.8)^{* \wedge}$ & $7.6(4.1-10.1)^{*}$ & 0.022 \\
\hline
\end{tabular}

Variables are expressed as median and $95 \%$ confidence interval $(95 \% \mathrm{CI}){ }^{\circ} \mathrm{P}$-value obtained by Kruscall Wallis test. ${ }^{*} \mathrm{P}<0.05$ vs healthy liver; ${ }^{*} \mathrm{P}<0.05$ vs stage $0 ;{ }^{\wedge} \mathrm{P}<0.05$ vs stage $1 ;{ }^{* *} \mathrm{P}<0.01$ vs healthy liver; ${ }^{\circledR} \mathrm{P}<0.01$ us stage 1 , obtained by Mann Whitney test. 


\section{HSC/MF markers expression and ductular reaction}

The DR score, evaluated by CK7, increased with fibrosis progression $(\mathrm{r}=0.57$; $\mathrm{P}<0.0001$ ), and a positive correlation was found between the DR score and the number of lobular HSCs/MFs quantified with the different markers tested $(\mathrm{r}=0.44$ $\mathrm{P}=0.004$ for $\mathrm{DR}$ vs CRBP-1; $\mathrm{r}=0.48$ $\mathrm{P}=0.004$ for $\mathrm{DR}$ vs alpha-SMA). Interestingly HPCs of DR were typically found in close proximity to Reelin positive HSCs/MFs (Figure 6A) and a positive correlation was found between the DR and Reelin positive lobular HSCs/MFs ( $\mathrm{r}=0.38$; $\mathrm{P}=0.01$ ) (Figure $6 \mathrm{~B}$ ). A positive correlation was also found between DR score and portal/septal HSCs/MFs, identified by CRBP-1 $(\mathrm{r}=0.48 ; \mathrm{P}=0.007)$ or alpha-SMA $(\mathrm{r}=0.56$; $\mathrm{P}=0.001)$ but not Reelin $(\mathrm{r}=0.08 ; \mathrm{P}=0.6)$ expression. By multivariate linear regression analysis, the association between Reelin -positive lobular HSCs/MFs and DR was shown to be independent of the number of alpha-SMA-positive and CRBP-1-positive lobular $\mathrm{HSCs} / \mathrm{MFs}(\mathrm{P}=0.01)$.

\section{Discussion}

In this study, we demonstrated that Reelin is expressed by human HSCs/MFs and that the Reelin positive lobular HSCs/MFs significantly increased during liver fibrosis progression. Reelin is a serine protease of the extracellular matrix which rapidly degrades fibronectin and laminin, ${ }^{43}$ and that its expression and function are well described in brain development and maturation. Smalheiser et al. reported Reelin plasma levels thought to be produced by liver tissue. ${ }^{9}$ Samama et al. demonstrated Reelin expression in the spindle-shaped cells of fetal and adult rat liver and human liver identified as stellate (Ito) cells. ${ }^{11}$

Here, in a cohort of HCV patients, we demonstrated a significant positive correlation between Reelin positive lobular HSCs/MFs and the stage of liver fibrosis stage. These results are in line with BotellaLopez et al. who demonstrated increased Reelin levels in the liver and plasma of bile duct ligated (BDL) rats. ${ }^{13}$ They also observed a marked increase increase in levels of the Reelin protein in cirrhotic livers of BDL rats accompanied by an increase in mRNA transcripts compared to sham-operated controls. ${ }^{13}$ In this scenario, in line with Mansy et $a l .{ }^{15}$, the increase of Reelin expression in different stages of chronic HCV liver disease suggests its role in HSC activation and consequently in liver fibro-
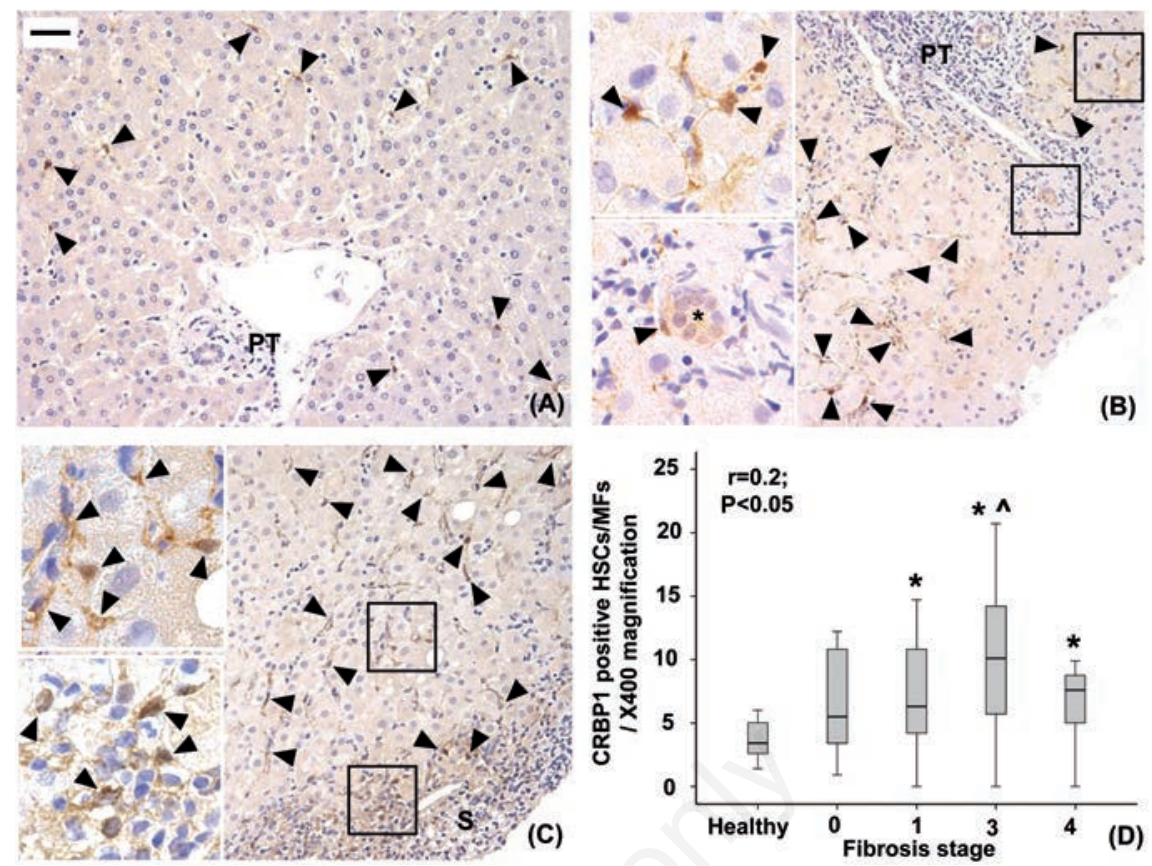

Figure 3. Immunohistochemical expression of CRBP-1 in healthy livers (A), livers with mild-moderate fibrosis (B) and with severe fibrosis (C). CRBP-1 positive hepatic stellate cells/myofibroblasts are mainly found in the hepatic lobule and to a lesser degree in the portal tracts (PT) and septa (S) (arrowheads). Their number increases as the fibrosis progresses $\left(\mathrm{r}=0.2, \mathrm{P}<0.05 ;{ }^{*} \mathrm{P}<0.05\right.$ vs healthy liver, ${ }^{\wedge} \mathrm{P}<0.05$ vs stage $\left.1, \mathrm{D}\right)$. A scant $\mathrm{CRBP}-1$ expression is observed in some interlobular bile ducts $(*)$. Original magnification; X200; high power fields: X400; scale bar: $50 \mu \mathrm{m}$.
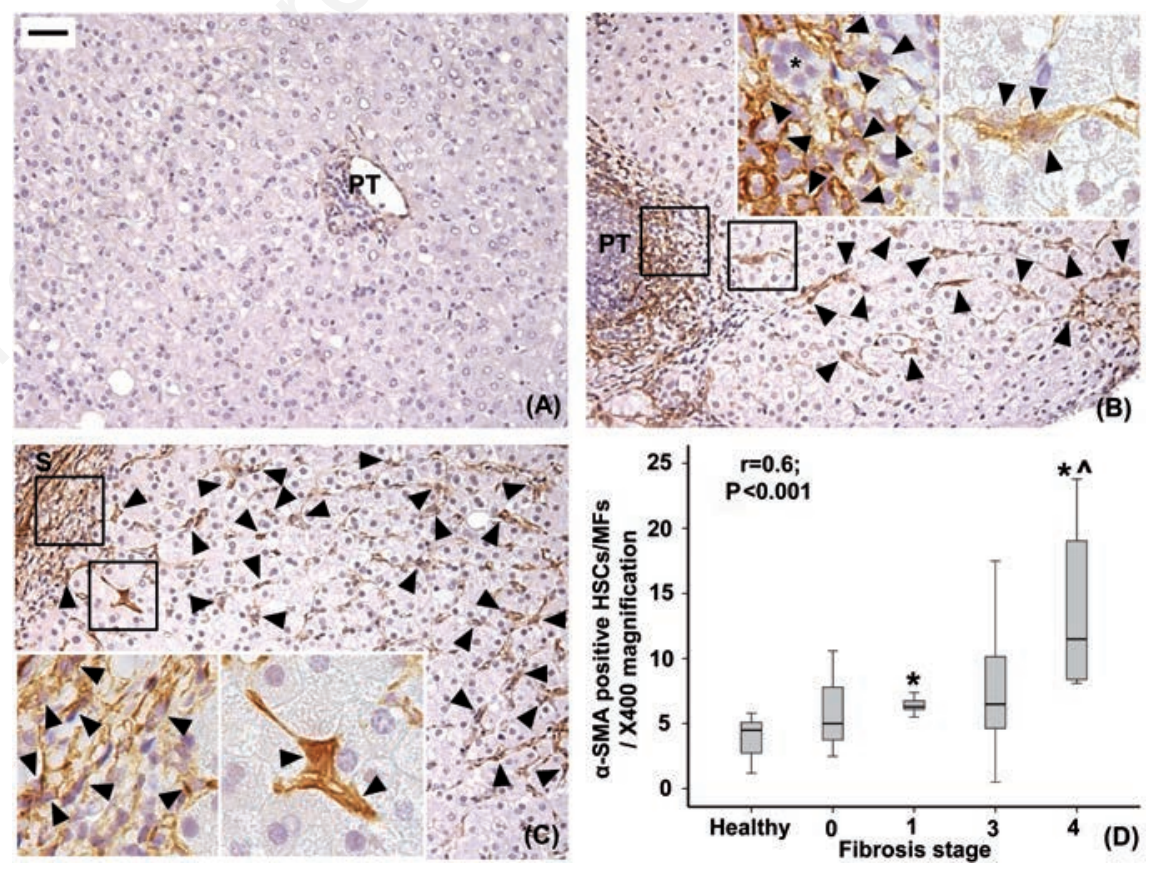

Figure 4. Immunohistochemical expression of alpha-SMA in healthy livers (A), livers with mild-moderate fibrosis $(B)$ and with severe fibrosis $(C)$. Only very few alpha-SMApositive hepatic stellate cells/myofibroblasts (arrowheads) are found in healthy livers and are individuated in the lobule, enlarged portal tract (PT) and septa (S) in fibrotic livers. The number of lobular alpha-SMA-positive hepatic stellate cells increases as fibrosis progresses $\left(\mathrm{r}=0.6, \mathrm{P}<0.001 ;{ }^{*} \mathrm{P}<0.01\right.$ vs healthy liver, $\wedge^{\wedge} \mathrm{P}<0.01$ vs stage $\left.1, \mathrm{D}\right)$. A control alphaSMA-negative interlobular bile duct is indicated $(*)$. Original magnification; X200; high power fields: X400; scale bar: $50 \mu \mathrm{m}$. 
genesis. In order to explore the role of Reelin in liver fibrosis progression, the HSCs/MFs compartment of our cohort of patients was investigated. CRBP-1 is a key component of the retinoid signalling pathway and is highly expressed in both normal and pathological liver samples. ${ }^{24,25} \mathrm{We}$ found a relatively low number of CRBP-1 cells in normal human liver and a progressive and significant increase of CRBP-1 HSCs/MFs during the hepatic fibrogenic process. These data, confirming the key role of $\mathrm{HSCs} / \mathrm{MFs}$ in liver disease, ${ }^{20}$ demonstrate the expansion of HSCs/MFs compartment during liver fibrosis. With regards HSC activation, alpha-SMA protein, a proven marker of fully activated HSCs/MFs, as already demonstrated in previous studies, ${ }^{20}$ was also investigated. Our data showed a significant correlation between CRBP-1 and alpha-SMA positive lobular HSCs/MFs. Taken together, these results confirm that the process of liver fibrosis is mediated by both the proliferation and activation of $\mathrm{HSCs} / \mathrm{MFs} .^{44}$ Interestingly, despite the association shown to exist between Reelin positive and CRBP1 positive HSCs/MFs, at least in the lobule, no relationship was found between Reelin and alpha-SMA positive HSCs/MFs. This suggests that Reelin should not be regarded as a marker of HSCs differentiation but rather as a functional protein expressed by HSCs/MFs during some phases of liver fibrosis progression, possibly linked with HSCs/MFs migration activities. Moreover, Reelin expression was found mainly in the lobules rather than in the portal tracts and septa. Taking into account that HSCs/MFs comprise mesenchymal cell populations of different origin with myofibroblast-like features, ${ }^{17}$ Reelin could be mainly exhibited by HSCs/MFs originating from perisinusoidal HSCs in the lobule. Since these cells have recently been implicated as being primarily responsible for liver fibrosis, irrespective of its etiology, ${ }^{45}$ the findings of this study suggest that further investigations into the role of Reelin in the hepatic fibrogenic process are required. Our data also showed Dab1 immunoreactivity in the cytoplasm and in the nuclei of bile ducts of DR and also, to a lesser degree, in the normal bile ducts of the portal tracts. Dab1 expression has never been investigated in human liver tissue. Actually, Smalheiser et al. did not find Dab1 expression in adult rat liver, either by immunocytochemistry or Western blotting. ${ }^{9}$ This result, which is in apparent contrast with our findings, could be partly attributed to the relative poor number of liver cells expressing the Dab1 receptor in physiological conditions. Indeed, in our cohort of patients with liver disease in which DR is conspicuous, Dab1 immunoreactive cells were readily found. The Dab1 expression in DR cells suggest that Reelin might exert its function through its paracrine effect on liver tissue rather than being secreted into the blood for action on distal target(s), as previously suggested. ${ }^{9}$

Moreover, HPCs are found in the DR compartment. They are able to differentiate between a cholangiocyte and a hepatocyte cell line in the course of prolonged liver injury when the replicative capacity of hepatocytes is compromised. ${ }^{27}$ HPCs and DR are also able to promote hepatic fibrogenesis through their interaction with HSCs in the course of a chronically persistent liver injury. Mediators produced by cells of DR have been proven to induce HSCs activation $^{46,47}$ and an enhanced pro-fibrogenic

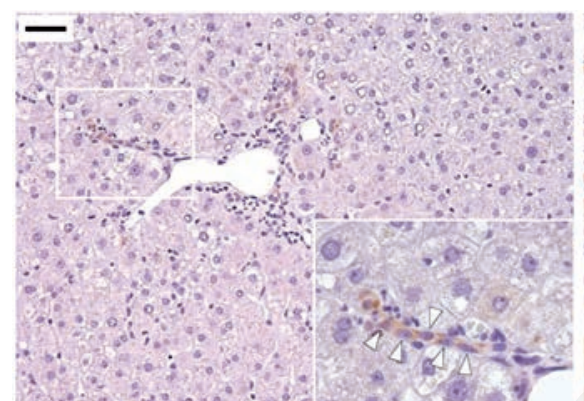

(A):
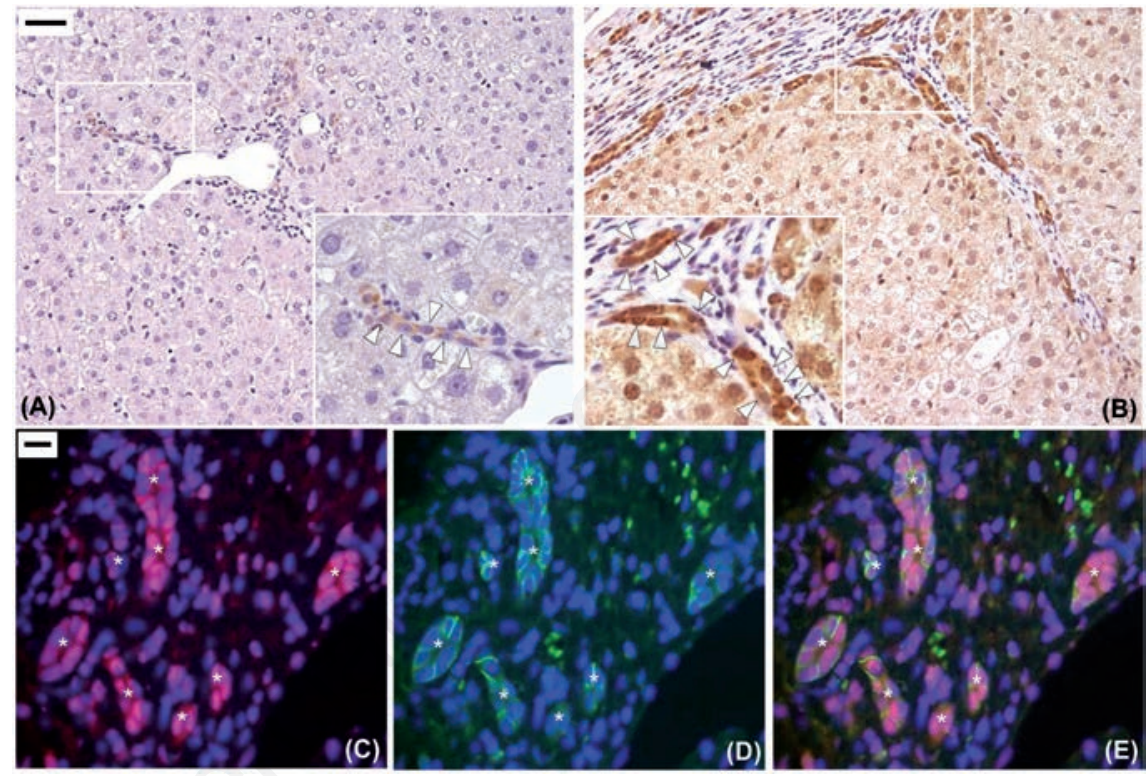

Figure 5. Immunohistochemical expression of Dab1. In the healthy liver, only a faint expression of Dab1 was detected in a few ducts and ductules in the portal area (open arrowheads, A). Increased expression of disabled-1 protein was found in the biliary ducts and ductules of ductular reaction in the diseased liver with severe fibrosis (open arrowheads, B). Double-labelling experiments confirmed that Dab1 (red) was expressed at cytoplasmic and nuclear level by biliary cells of ductules of ductular reaction (asterisks) with the progenitor cell's phenotype (EpCAM-positive cells, green) (C-E). Original magnification: X200 with high power fields X400 (A,B), X600 (C-E); scale bars: A,B), $50 \mu \mathrm{m}$; C-E), $10 \mu \mathrm{m}$.
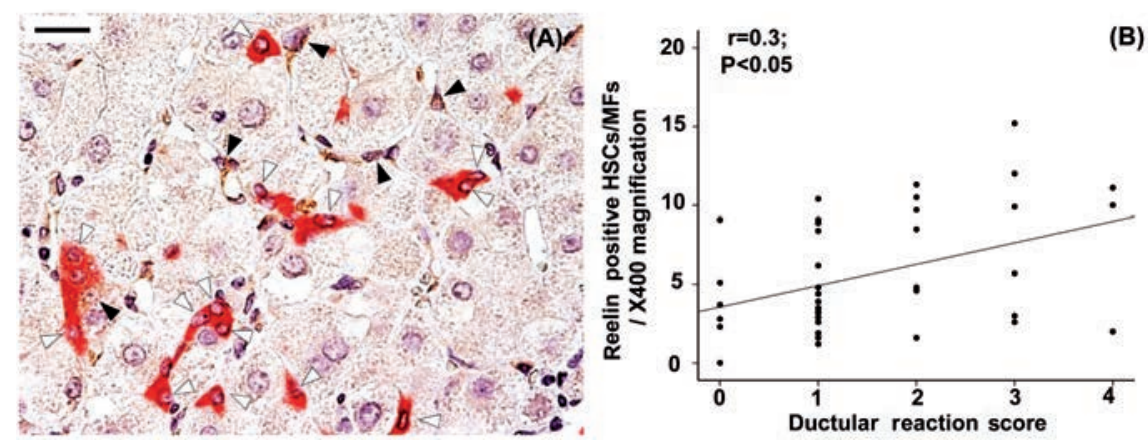

Figure 6. Relationship between Reelin-expressing hepatic stellate cells and cells of ductular reaction. Cells with the morphological features of progenitor cells (CK19-positive cells that are isolated or grouped in strings, open arrowheads) were seen close to Reelin positive hepatic stellate cells (closed arrowheads) in the periportal area with ductular reaction (A). A positive correlation was found between the number of Reelin-positive hepatic stellate cells and the ductular reaction score $(r=0.3, P<0.05, B)$. Original magnification: X400; scale bar: $20 \mu \mathrm{m}$. 
response has been found during HPCs activation in animal models ${ }^{48,49}$ and in human liver pathologies. ${ }^{34,50}$ In this study an association was also observed between the expression of DR and HSC markers. Interestingly Reelin-positive lobular HSCs/MFs were associated with DR irrespective of the number of both alpha-SMApositive and CRBP-1-positive lobular HSCs/MFs. Moreover, the finding of Dab1 expression in HPCs of DR further supports the belief that Reelin could play a role in the regulation of HPCs. In this scenario, Reelin HSCs/MFs secretion may have a role in both restoring the mass of damaged hepatocyte cells and in further promoting liver fibrogenesis through HPCs activation. This putative role for Reelin in the activation of the progenitor compartment following tissue injury was also suggested in other damaged organs such as the retina and cornea. ${ }^{51}$ The role of Reelin in regulating the trafficking of stem cells in different injured tissues could be investigated since this protein activity mimics its function in normal organogenesis.

This study is based on the results obtained from human liver tissue taken from clinical biopsy specimens with the aim of investigating Reelin expression at different stages of human liver disease. Functional in vitro experiments are needed in order to explore the effective role and function of Reelin protein in liver disease.

In conclusion, this study demonstrates that Reelin expression correlates significantly with stages of liver fibrosis and suggest, for the first time, that Reelin is involved in the cross-talk between HSCs/MFs and HPCs of DR during liver injury. Reelin may represent a useful biomarker for assessing the progress of liver fibrosis and may thus be potentially incorporated in liver injury evaluation in combination with other histological data. Further research into the role of Reelin in liver injury will make a helpful contribution towards understanding the mechanisms of fibrosis development in patients with chronic hepatitis $\mathrm{C}$.

\section{References}

1. Rice DS, Curran T. Role of the Reelin signaling pathway in central nervous system development. Annu Rev Neurosci 2001;24:1005-39.

2. Jossin Y, Bar I, Ignatova N, Tissir F, De Rouvroit CL, Goffinet AM. The Reelin signaling pathway: some recent developments. Cereb Cortex 2003;13:62733.
3. Curran T, D'Arcangelo G. Role of Reelin in the control of brain development. Brain Res Brain Res Rev 1998; 26:285-94.

4. Frotscher M. Cajal-Retzius cells, Reelin, and the formation of layers. Curr Opin Neurobiol 1998;8:570-5.

5. Tissir F, Goffinet AM. Reelin and brain development. Nat Rev Neurosci 2003; 4:496-505.

6. Trommsdorff M, Gotthardt M, Hiesberger T, Shelton J, Stockinger W, Nimpf J, et al. Reeler/Disabled-like disruption of neuronal migration in knockout mice lacking the VLDL receptor and ApoE receptor 2. Cell 1999;97:689701.

7. Howell BW, Herrick TM, Hildebrand JD, Zhang Y, Cooper JA. Dab1 tyrosine phosphorylation sites relay positional signals during mouse brain development. Curr Biol 2000;10:877-85.

8. Ikeda Y, Terashima T. Expression of Reelin, the gene responsible for the reeler mutation, in embryonic development and adulthood in the mouse. Dev Dyn 1997;210:157-72.

9. Smalheiser NR, Costa E, Guidotti A, Impagnatiello F, Auta J, Lacor P, et al. Expression of Reelin in adult mammalian blood, liver, pituitary pars intermedia, and adrenal chromaffin cells. Proc Natl Acad Sci USA 2000;97:12816.

10. Kobold D, Grundmann A, Piscaglia F, Eisenbach C, Neubauer K, Steffgen J, et al. Expression of Reelin in hepatic stellate cells and during hepatic tissue repair: a novel marker for the differentiation of HSC from other liver myofibroblasts. J Hepatol 2002;36:607-13.

11. Samama B, Boehm N. Reelin immunoreactivity in lymphatics and liver during development and adult life. Anat Rec A Discov Mol Cell Evol Biol 2005;285: 595-9.

12. Magness ST, Bataller R, Yang L, Brenner DA. A dual reporter gene transgenic mouse demonstrates heterogeneity in hepatic fibrogenic cell populations. Hepatology 2004;40:1151-9.

13. Botella-Lopez A, De Madaria E, Jover R, Bataller R, Sancho-Bru P, Candela A, et al. Reelin is overexpressed in the liver and plasma of bile duct ligated rats and its levels and glycosylation are altered in plasma of humans with cirrhosis. Int J Biochem Cell Bio. 2008; 40:766-75.

14. WHO [Internet]. Geneva: World Health Organization; Hepatitis C, fact sheet [updated July 2016]. Available from: www.who. int/mediacentre/factsheets/fs164/en
15. Mansy SS, Nosseir MM, Zoheiry MA, Hassanein MH, Guda MF, Othman MM et al. Value of Reelin for assessing hepatic fibrogenesis in a group of Egyptian HCV infected patients. Clin Chem Lab Med 2014;52:1319-28.

16. Hernandez-Gea V, Friedman SL. Pathogenesis of liver fibrosis. Annu Rev Pathol 2011;6:425-56.

17. Friedman SL. Hepatic stellate cells: protean, multifunctional, and enigmatic cells of the liver. Physiol Rev 2008; $88: 125-72$.

18. Blomhoff R, Wake K. Perisinusoidal stellate cells of the liver: important roles in retinol metabolism and fibrosis. FASEB J 1991;5:271-7.

19. Roskams T. Relationships among stellate cell activation, progenitor cells, and hepatic regeneration. Clin Liver Di. 2008;12:853-60.

20. Carpino G, Morini S, Ginanni Corradini S, Franchitto A, Merli M, Siciliano M, et al. Alpha-SMA expression in hepatic stellate cells and quantitative analysis of hepatic fibrosis in cirrhosis and in recurrent chronic hepatitis after liver transplantation. Dig Liver Dis 2005;37: 349-56.

21. Carotti S, Morini S, Corradini SG, Burza MA, Molinaro A, Carpino G, et al. Glial fibrillary acidic protein as an early marker of hepatic stellate cell activation in chronic and posttransplant recurrent hepatitis C. Liver Transpl 2008;14:806-14.

22. Gawrieh S, Papouchado BG, Burgart LJ, Kobayashi S, Charlton MR, Gores GJ. Early hepatic stellate cell activation predicts severe hepatitis $\mathrm{C}$ recurrence after liver transplantation. Liver Transpl 2005;11:1207-13.

23. Schmitt-Gräff A, Krüger S, Bochard F, Gabbiani G, Denk H. Modulation of alpha smooth muscle actin and desmin expression in perisinusoidal cells of normal and diseased human livers. Am J Pathol 1991;138:1233-42.

24. Van Rossen E, Vander Borght S, Van Grunsven LA, Reynaert H, Bruggeman V, Blomhoff R, et al. Vinculin and cellular retinol-binding protein-1 are markers for quiescent and activated hepatic stellate cells in formalin-fixed paraffin embedded human liver. Histochem Cell Biol 2009;131:313-25.

25. Lepreux S, Bioulac-Sage P, Gabbiani G, Sapin V, Housset C, Rosenbaum J, et al. Cellular retinol-binding protein-1 expression in normal and fibrotic/cirrhotic human liver: different patterns of expression in hepatic stellate cells and (myo)fibroblast subpopulations. J 
Hepatol 2004;40:774-80.

26. Van Hul NK, Abarca-Quinones J, Sempoux C, Horsmans Y, Leclercq IA. Relation between liver progenitor cell expansion and extracellular matrix deposition in a CDE-induced murine model of chronic liver injury. Hepatology 2009;49:1625-1635.

27. Carpino G, Renzi A, Franchitto A, Cardinale V, Onori P, Reid L, et al. Stem/progenitor cell niches involved in hepatic and biliary regeneration. Stem Cells Int 2016;2016:3658013.

28. Desmet V, Roskams T, Van Eyken P. Ductular reaction in the liver. Pathol Res Pract. 1995;191:513-24.

29. Clouston AD, Powell EE, Walsh MJ, Richardson MM, Demetris AJ, Jonsson JR. Fibrosis correlates with a ductular reaction in hepatitis $C$ : roles of impaired replication, progenitor cells and steatosis. Hepatology 2005;41:809-18.

30. Richardson MM, Jonsson JR, Powell EE, Brunt EM, Neuschwander-Tetri BA, Bhathal PS, et al. Progressive fibrosis in nonalcoholic steatohepatitis: association with altered regeneration and a ductular reaction. Gastroenterology 2007;133:80-90.

31. Spee B, Carpino G, Schotanus BA, Katoonizadeh A, Vander Borght S, Gaudio E, et al. Characterisation of the liver progenitor cell niche in liver diseases: potential involvement of Wnt and Notch signalling. Gut 2010;59:247-57.

32. Turner R, Lozoya O, Wang Y, Cardinale V, Gaudio E, Alpini G, et al. Human hepatic stem cell and maturational liver lineage biology. Hepatology 2011; 53:1035-45.

33. Vespasiani-Gentilucci U, Carotti S, Perrone G, Mazzarelli C, Galati G, Onetti-Muda A, et al. Hepatic toll-like receptor 4 expression is associated with portal inflammation and fibrosis in patients with NAFLD. Liver Int. 2015;35:569-81.

34. Carotti S, Vespasiani-Gentilucci U,
Perrone G, Picardi A, Morini S. Portal inflammation during NAFLD is frequent and associated with the early phases of putative hepatic progenitor cell activation. J Clin Pathol 2015;68: 883-90.

35. Brunt EM. Grading and staging the histopathological lesions of chronic hepatitis: the Knodell histology activity index and beyond. Hepatology 2000; 31:241-6.

36. Roskams TA, Theise ND, Balabaud C, Bhagat G, Bhathal PS, Bioulac-Sage P, et al. Nomenclature of the finer branches of the biliary tree: canals, ductules, and ductular reactions in human livers. Hepatology 2004;39:1739-45.

37. Gadd VL, Skoien R, Powell EE, Fagan KJ, Winterford C, Horsfall L, et al. The portal inflammatory infiltrate and ductular reaction in human nonalcoholic fatty liver disease. Hepatology 2014;59:1393-405.

38. Cassiman D, Libbrecht L, Desmet V, Denef C, Roskams T. Hepatic stellate cell/myofibroblast subpopulations in fibrotic human and rat livers. J Hepatol 2002;36:200-9.

39. Vespasiani-Gentilucci U, Carotti S, Onetti-Muda A, Perrone G, GinanniCorradini S, Latasa MU et al. Toll-like receptor-4 expression by hepatic progenitor cells and biliary epithelial cells in HCV-related chronic liver disease. Mod Pathol 2012;25:576-89.

40. Perrone G, Vincenzi B, Zagami M, Santini D, Panteri R, Flammia G, et al. Reelin expression in human prostate cancer: a marker of tumor aggressiveness based on correlation with grade. Mod Pathol. 2007;20:344-51.

41. Bior BK, Ballif BA. Dab1 stabilizes its interaction with Cin 85 by suppressing Cin85 phosphorylation at serine 587 . FEBS Lett.2013;587:60-6.

42. Lua I, Li Y, Zagory JA, Wang KS, French SW, Sévigny $J$ et al. Characterization of hepatic stellate cells, portal fibroblasts, and mesothelial cells in normal and fibrotic livers. J Hepatol 2016;64:1137-46.

43. Quattrocchi CC, Wannenes F, Persico AM, Ciafré SA, D'Arcangelo G, Farace $\mathrm{MG}$, et al. Reelin is a serine protease of the extracellular matrix. J Biol Chem 2002;277:303-9.

44. Friedman SL. Evolving challenges in hepatic fibrosis. Nat Rev Gastroenterol Hepatol 2010;7:425-36.

45. Mederacke I, Hsu CC, Troeger JS, Huebener P, Mu X, Dapito DH, et al. Fate tracing reveals hepatic stellate cells as dominant contributors to liver fibrosis independent of its aetiology. Nat Commun 2013;4:2823.

46. Theise ND, Kuwahara R. The tissue biology of ductular reactions in human chronic liver disease. Gastroenterology 2007;133:350-2.

47. Omenetti A, Choi S, Michelotti G, Diehl AM. Hedgehog signaling in the liver. J Hepatol 2011;54:366-73.

48. Kuramitsu K, Sverdlov DY, Liu SB, Csizmadia E, Burkly L, Schuppan D, et al. Failure of fibrotic liver regeneration in mice is linked to a severe fibrogenic response driven by hepatic progenitor cell activation. Am J Pathol 2013; 183:182-194.

49. Peng ZW, Ikenaga N, Liu SB, Sverdlov DY, Vaid KA, Dixit R, et al. Integrin alphavbeta6 critically regulates hepatic progenitor cell function and promotes ductular reaction, fibrosis, and tumorigenesis. Hepatology 2016;63:217-232.

50. Nobili V, Carpino G, Alisi A, Franchitto A, Alpini G, De Vito R, et al. Hepatic progenitor cells activation, fibrosis, and adipokines production in pediatric nonalcoholic fatty liver disease. Hepatology 2012;56:2142-53.

51. Pulido JS, Sugaya I, Comstock J, Sugaya K. Reelin expression is upregulated following ocular tissue injury. Graefes Arch Clin Exp Ophthalmol 2007;245:889-93. 